\title{
Thyrotropin Behavior in Thyroid Disorders of Childhood
}

\author{
Alberto Hayek ${ }^{[51]}$, Farahe Maloof, and John D. Crawford \\ Departments of Pediatrics and Medicine, Harvard Medical School, and the Children's and Medical Services, Massachusetts General Hospital, \\ Boston, Massachusetts, USA
}

\begin{abstract}
Through the use of a double antibody radioimmunoassay method, the mean serum concentration of thyrotropin (TSH) in 51 normal children aged 1 month-18 years was $3.7 \mathrm{ng} / \mathrm{ml}$. There was no change with age, sex, or time of the day at which the sample was obtained.

In six of nine newly diagnosed hyperthyroid children concentrations of TSH fell below the limit of detection, whereas in the remaining three concentrations were in the low normal range. Knowledge of the TSH fluctuations during medical treatment (antithyroid drugs or radioactive iodine plus ${ }^{127} \mathrm{I}$ ) were useful in insuring a smooth clinical course. Elevations in TSH above $10 \mathrm{ng} / \mathrm{ml}$ served to indicate a need for change in therapy. Radical subtotal thyroidectomy evoked an acute compensatory rise $(>20$ $\mathrm{ng} / \mathrm{ml}$ ) in TSH levels which was sometimes sufficient to maintain the level of serum thyroxine above $4 \mu \mathrm{g} / 100 \mathrm{ml}$. Hemithyroidectomy did not influence TSH or other thyroid parameters in previously euthyroid subjects.

There was a clear separation between normal subjects and patients with primary hypothyroidism with values for TSH always exceeding $20 \mathrm{ng} / \mathrm{ml}$ in the latter. The TSH levels were below $3.7 \mathrm{ng} / \mathrm{ml}$ in pituitary hypothyroidism. In hypothyroid patients receiving adequate replacement therapy, elevations of serum TSH of $>20 \mathrm{ng} / \mathrm{ml}$ were encountered 2 weeks after discontinuation of treatment.

Investigation of the pituitary-thyroidal axis in two untreated cretinous infants showed preservation of the functional integrity of the pituitary-thyroidal feedback system despite prenatal thyroid insufficiency as evidenced by a fall of TSH from levels $>80$ to $<5 \mathrm{ng} / \mathrm{ml}$ in the presence of free thyroxine $\left(\mathrm{FT}_{4}\right)$ levels $>2 \mathrm{ng} / 100 \mathrm{ml}$.

In three patients (two females and one male) with longstanding juvenile hypothyroidism and $\mathrm{TSH}$ levels $>80 \mathrm{ng} / \mathrm{ml}$, pituitary dysfunctions characterized by luteinizing hormone $(\mathrm{LH})$ concentrations above $20 \mathrm{mIU} / \mathrm{ml}$ and blunted growth hormone (HGH) responses to hypoglycemia were documented prior to therapy. Only the male had evidence of sexual precocity on physical examination. All three showed an abnormal circadian rhythm of cortisol secretion manifested by 8 PM values greater than $10 \mu \mathrm{g} / 100 \mathrm{ml}$. Acute restoration of euthyroidism in the two girls by means of parenteral thyroxine $\left(\mathrm{T}_{4}\right)$ improved the $\mathrm{HGH}$ response and normalized the cortisol rhythms in $72 \mathrm{hr}$, coincident with a sharp decline in TSH levels toward normal. In contrast, the high levels of LH declined much more slowly, failing to reach normal for as long as 7 weeks posttreatment.

TSH in company with $\mathrm{T}_{4}$ measurements permitted segregation of patients with Hashimoto's thyroiditis into three groups: $(a)$ euthyroid with normal TSH and $\mathrm{T}_{4}$,
\end{abstract}


(b) compensated with TSH values ranging between 19 and $28 \mathrm{ng} / \mathrm{ml}$ and $\mathrm{T}_{4}$ in the $6-8$ $\mu \mathrm{g} / 100 \mathrm{ml}$ range, and $(c)$ hypothyroid with $\mathrm{T}_{4}$ below $3 \mu \mathrm{g} / 100 \mathrm{ml}$ and $\mathrm{TSH}$ values greater than $40 \mathrm{ng} / \mathrm{ml}$.

\section{Speculation}

High peripheral concentrations of serum TSH appear to be the most sensitive index of primary hypothyroidism and will thus be useful both in establishing diagnosis and in determining the adequacy of treatment.

Elevated gonadotropin levels appear to be the rule in longstanding juvenile hypothyroidism, but physical evidence of sexual precocity seems to be an unusual feature in the syndrome. This may suggest subnormal secretory responsiveness of the gonadal target organs, or subnormal sensitivity of the tissues responsible for secondary sexual differentiation.

The observation that patients with cretinism and juvenile myxedema can be safely rendered euthyroid by therapy which abruptly returns serum thyroxine concentration to normal and promptly corrects the associated hypothalamic and pituitary dysfunctions suggests that conventional therapy can be improved. A more aggressive approach to treatment of the infant cretin may reduce the still high incidence of mental subnormality as has been suggested recently [32].

\section{Introduction}

Information has recently become available concerning the concentration of TSH in the preterm fetus [7, 10], the newborn $[6,8,9]$, and in children affected with certain specific thyroid disorders [11,21]. These measurements have helped to refine our concepts of the development and the functions of the hypothalamic-pituitary-thyroidal axis in health and disease. It is the purpose of this report to recount our experiences with measurement of TSH in both normal children and those affected with the classical thyroid diseases in order to emphasize its utility in diagnosis, management, and prognosis.

\section{Materials}

Serum TSH radioimmunoassay was carried out according to the method of Odell et al. [30] and of Utiger [39], modified as described below. Human TSH (hTSH) and anti-h-TSH serum were highly purified preparations [43]. Human Thyrotropin Research Standard A was used as the primary standard for these assays [44].

The NIH h-TSH was used for labeling and to prepare large pools of secondary standards (assayed against the primary standard) which were aliquoted and used for routine assays. Conversion from nanograms per milliliter to microunits per milliliter of serum (based on Research Standard A) is effected by multiplying the former values by a conversion factor of 1.4. ${ }^{125}$ I-labeled h-TSH was prepared using the general procedure of Hunter and Greenwood [17]. The labeled h-TSH was separated from inorganic ${ }^{125} \mathrm{I}$ by passage through a column of Sephadex G-50 using phosphate-buffered saline $(0.01 \mathrm{~m}$ phosphate buffer, $\mathrm{pH} 7.8$ in $0.9 \% \mathrm{NaCl})$. About $50 \%$ of the ${ }^{125} \mathrm{I}$ is incorporated into the h-TSH by this procedure, yielding specific activities of about $50 \mathrm{mCi} / \mathrm{mg}$. The total volume of $1.01 \mathrm{ml}$ in each assay tube contained rabbit anti-hTSH serum $(1: 200,000)$, normal rabbit serum $(1: 125)$, chorionic gonadotrophin (5 IU), ethylenediaminetetraacetic acid $(0.01 \mathrm{M})$, standard or unknown $(0.2$ $\mathrm{mI})$, and ${ }^{125}$ I-labeled TSH (0.09 $\left.\mathrm{ng}\right)$, all in phosphatebuffered saline. After incuabtion at $4^{\circ}$ for 6 days, the h-TSH-125I bound to anti-h-TSH antibody was precipitated by the addition of goat anti-rabbit $\gamma$-globulin. Corrections for counts trapped nonspecifically in the precipitate were made by subtracting an average "blank" count from the counts in the standard and unknown assay tubes. These corrected counts were expressed as percentages of the counts initially added to each assay tube, and a graph of these percentages versus TSH concentration was drawn from the data for the standard tubes. Values for the unknowns are read directly from this graph. Thus, the values reported are the nanograms of Human Thyrotropin Research Standard A per milliliter in a standard sample which, when assayed, yields the same percentage of activity 
bound as was bound in the assay of the unknown sample.

Values were reported as averages of the duplicate determinations for a sample when the duplicate results were within $10 \%$ of each other. The reproducibility of reported values from assay groups done on different days was tested by assaying aliquots from three large serum pools repeatedly. Results from 19 different assay groups over a 3-month period gave the following mean TSH concentrations and standard deviations for these pools: $3.4 \pm 0.6 \mathrm{ng} / \mathrm{ml}, 10.6 \pm 1.6 \mathrm{ng} / \mathrm{ml}, 26.0 \pm 3.3$ $\mathrm{ng} / \mathrm{ml}$.

Within a given assay group results are more reproducible since the variation in the standard curve from group to group is absent. Results from 16 assays (8 pairs of duplicates) of aliquots from each of three serum pools, all assays done within a single group, gave the following pool means and standard deviations of duplicate averages about these means: $2.3 \pm 0.5$ $\mathrm{ng} / \mathrm{ml}, 15.0 \pm 1.2 \mathrm{ng} / \mathrm{ml}$.

Serum $\mathrm{T}_{4}[3]$ and $\mathrm{FT}_{4}[38]$ were measured [45] and triiodothyronine resin uptake $\left(\mathrm{T}_{3} \mathrm{U}\right)$ was determined [46]. Tanned red cell agglutinins and antibodies against cytoplasmic and colloid antigens were measured according to the methods described by Valloton et al. [41]. Plasma cortisol values were determined using Kliman's technique [21] and HGH level was measured according to the method of Catt et al. [4]. LH was measured using the radioimmunoassay method of Odell et al. [28, 29, 47].

\section{Subjects and Methods}

The "normal" subject population studied after obtaining appropriate informed consent comprised a group of 51 children, ranging in age from 1 month to 18 years. Some of these had been referred to our clinic because of small stature, but were found to have no recognizable endocrine, metabolic, or primary skeletal disease. The children with thyroid disorders included the following.

1. Nine were newly diagnosed thyrotoxic children. Of this group, three were eventually subjected to subtotal thyroidectomy, one was treated with radioiodine, and the rest were treated with the antithyroid drugs.

2. Two teenagers, a girl and a boy, aged 14 and 10 years, respectively, who underwent hemithyroidectomies on account of solitary thyroid nodules. Prior to operation, both were euthyroid. The girl had a "hot" nodule and the boy had a "cold" nodule as determined by ${ }^{131}$ I scans.
3. Twelve were patients diagnosed as having congenital hypothyroidism. This group included two untreated infants aged 3 weeks and 5 months, respectively, at the time of diagnosis. The younger was treated with small doses of $\mathbf{T}_{3}$ and desiccated thyroid, whereas the second patient received a priming dose of $300 \mu \mathrm{g}$ of $\mathrm{T}_{4}$ given parenterally as $100 \mu \mathrm{g}$ at 12 -hour intervals on the first day and $50 \mu \mathrm{g}$ twice on the second. The remaining 10 patients ranged in age between 5 and 18 years. All had been diagnosed prior to these studies and had been on replacement therapy.

4. A 14-year-old girl and a 33-year-old woman, both with hypothyroidism in association with sublingual thyroid tissue diagnosed by means of $99 \mathrm{~m} \mathrm{Tc}$ pertechnetate scans [13] were included. In these patients, as in the group above, thyroid replacement had been discontinued for 2 weeks prior to study.

5. Five were patients with hypothyroidism secondary to pituitary insufficiency associated with intra- or suprasellar tumors and who had had previous surgery. In all, history and complete pituitary evaluation revealed generalized failure of anterior pituitary function.

6 . Three were patients with juvenile hypothyroidism, a boy 12 years old and two prepuberal girls, 12 and 5.5 years old, each with profound, longstanding myxedema and enlargement of the sella turcica documented on skull x-rays. Whereas the girls exhibited all the classical findings of myxedema without evidence of sexual precocity the boy was brought to attention because of his short stature and disproportionately large testicular size. Although he lacked pubic or axillary hair, active spermatogenesis was documented by microscopic examination of fluid obtained from a prostatic massage. The girls were subjected to acute insulin-induced hypoglycemia prior to and $72 \mathrm{hr}$ after rapid restoration of euthyroidism with parenteral $T_{4}$ in doses of 500 and $400 \mu \mathrm{g}$, respectively, given in divided 12-hour doses of $100 \mu \mathrm{g}$. During each test, blood samples were obtained for blood sugar, LH, HGH, and cortisol. Cortisol rhythms were determined by 8 AM and 11 PM measurements. The male was treated conventionally with progressive increments in the dose of desiccated thyroid over a 2 month period.

7. Of 12 patients aged 5 to 16 years, with Hashimoto's thyroiditis, 11 were girls and 1 a boy. The diagnosis had been established by the presence of significant titers of thyroid antibodies, a $\mathrm{T}_{4}$ iodine protein-bound iodine discrepancy greater than $1.5 \mu \mathrm{g} / 100 \mathrm{ml}$, and histologic examination of the gland from material obtained by needle biopsy when both of the first two criteria were not fulfilled. 
Results

\section{Normal Subjects}

In the 51 normal children in whom peripheral serum TSH concentrations were measured, the mean was $3.7 \mathrm{ng} / \mathrm{ml}$, with values which ranged from less than 1 to $9.7 \mathrm{ng} / \mathrm{ml}$. In only a small percentage $(6 \%)$ was the result greater than $8 \mathrm{ng} / \mathrm{ml}$ (Fig. 1). As has been reported in the adult $[15,30]$, TSH levels in children were remarkably constant throughout the day; when serial determinations were performed at 4-hr intervals in three of the children, no changes greater than $0.5 \mathrm{ng} / \mathrm{ml}$ were encountered. No abrupt rise in TSH values paralleling those of $\mathrm{HGH}$ were observed when serum samples were obtained in four children 2 hr after initiation of sleep.

\section{Hyperthyroidism}

Serum concentrations of TSH were below $2.5 \mathrm{ng} / \mathrm{ml}$ in six of the group of nine newly diagnosed thyrotoxic children. In the other three children, values were normal (Fig. 1). This is in keeping with the general experience in thyrotoxic adults [30] who have shown undetectable, low, or normal levels [16].

\section{Medical Therapy}

Periodic determinations of TSH were of great usefulness in assessing the adequacy of medical or surgical

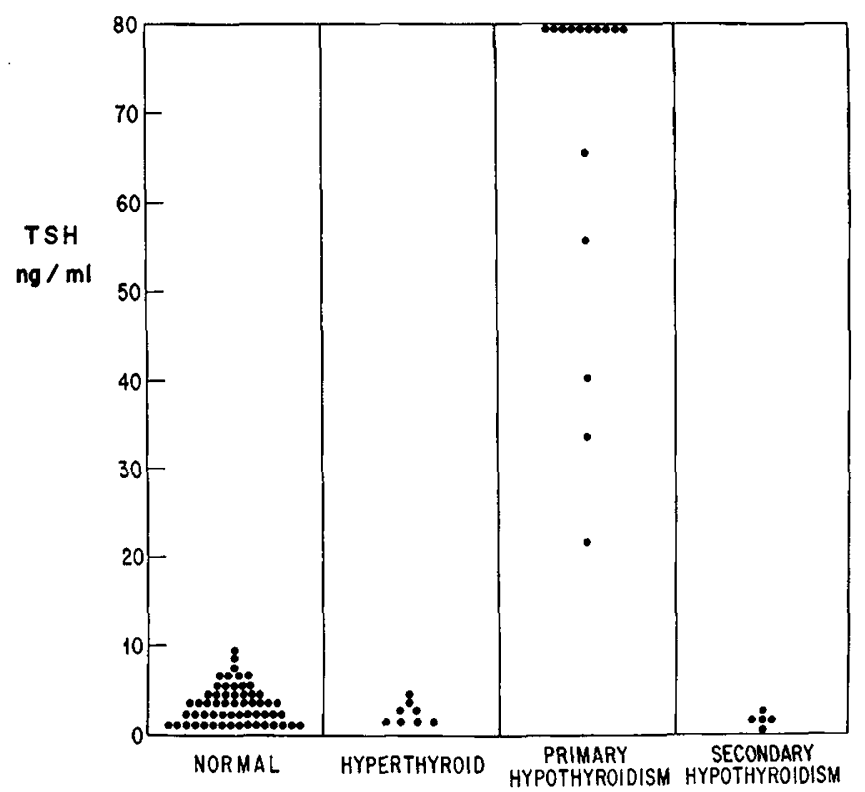

Fig. 1. Individual values for the concentrations of thyroid stimulating hormone $(T S H)$ in peripheral serum in normal, hyperthyroid, and hypothyroid children.

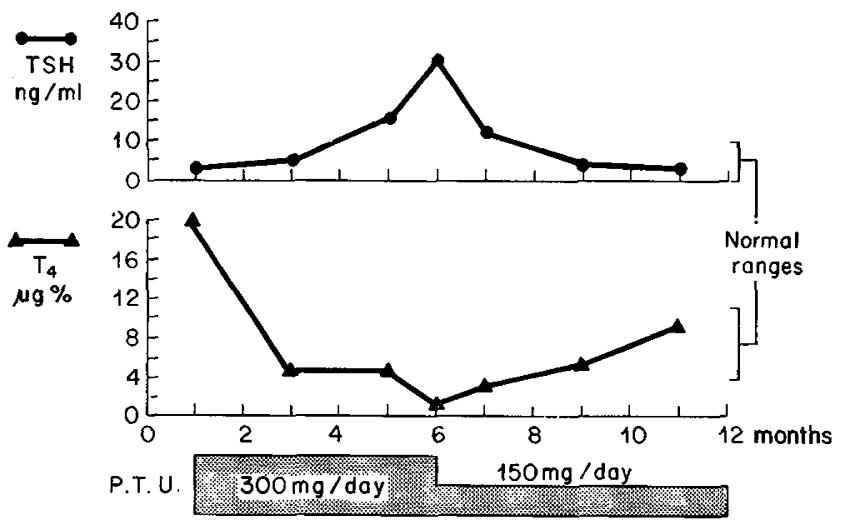

Fig. 2. Variations in thyroid stimulating hormone (TSH $)$ and in serum thyroxine $\left(T_{4}\right)$ in a hyperthyroid teenager treated with propylthiouracil.

therapy once the diagnosis of hyperthyroidism was confirmed by standard laboratory tests. This is illustrated in Figure 2 which gives data on a 13-year-old thyrotoxic boy treated with propylthiouracil. During the period of hypothyroidism, gross enlargement of the thyroid gland took place. A $50 \%$ decrease in the dose of propylthiouracil was followed by a return to normal of both the serum $\mathrm{T}_{4}$ and TSH concentrations.

\section{Radioiodine Therapy}

After radioiodine therapy it has been our policy to administer stable iodine as a means of achieving prompt symptomatic control until the effects of the radiation have taken place [14]. In patients so treated, a rise in the TSH level has indicated no further need for the stable iodine therapy. If continued too long, transient hypothyroidism induced by the "cold" iodine will be seen in many of these patients.

The usefulness of TSH measurements in following the course of a patient treated with radioiodine is illustrated by Figure 3. The subject of the figure was a 3-year-old girl with active thyrotoxicosis and intolerance to propylthiouracil at the time of radioiodine treatment. Potassium iodide ( $150 \mathrm{mg} / 24 \mathrm{hr}$ ) was begun 2 weeks later; the dose was doubled after 10 weeks because of persistent thyrotoxicity and a rise in $\mathrm{T}_{4}$ to $20 \mu \mathrm{g} / 100 \mathrm{ml}$. Thereafter, the $T_{4}$ fell, ultimately reaching subnormal values while the TSH rose above 40 $\mathrm{ng} / \mathrm{ml}$. These trends were reversed by discontinuing the stable iodine. The brief reinstitution of iodine caused a temporary reversal of the decline of TSH. In the 6 months since the last data on the figure, the child has remained euthyroid on no treatment although the TSH has not declined below $14 \mathrm{ng} / \mathrm{ml}$. 


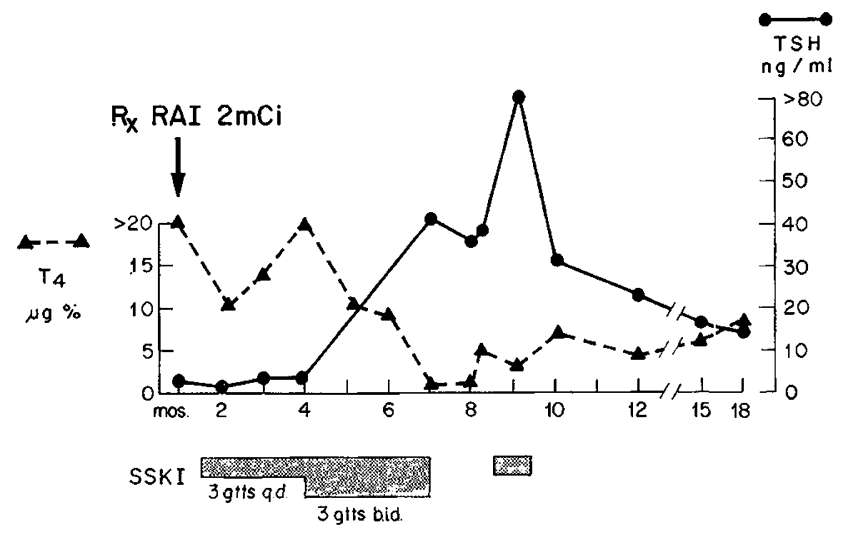

Fig. 3. Course of thyroid stimulating hormone (TSH) and of serum thyroxine $\left(T_{4}\right)$ values following treatment $\left(R_{x}\right)$ of thyrotoxicosis with radioiodine (RAI) and transient administration of stable iodine.

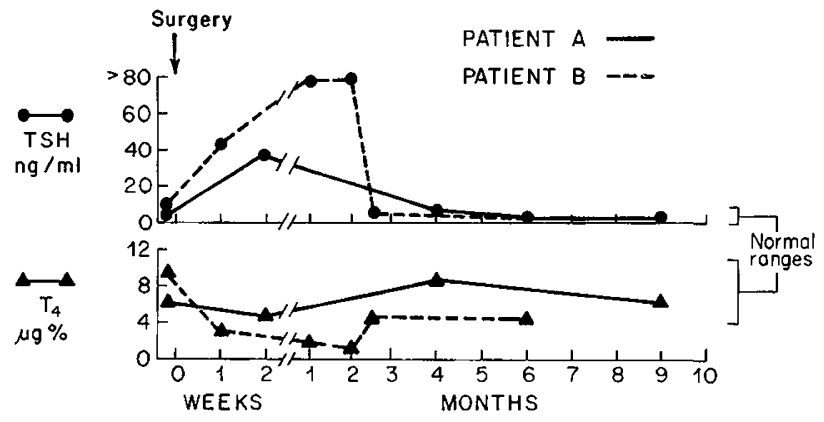

Fig. 4. Patterns of thyroid stimulating hormone (TSH) and of serum thyroxine $\left(T_{4}\right)$ response after subtotal thyroidectomy for thyrotoxicosis. The decrease of TSH in patient $B$ at 2 months followed institution of thyroid replacement therapy. Patient $A$ restored the TSH level to normal spontaneously.

\section{Surgical Therapy}

In the three thyrotoxic patients who underwent subtotal thyroidectomy, two patterns of response were observed as seen in Figure 4 . Within 2 weeks after surgery, the TSH became elevated whereas the concentration of serum $T_{4}$ remained normal or descended into the hypothyroid range. In the first instance (patient $A$ ), the thyroid remnant was adequate to maintain euthyroidism although transiently this required an elevated TSH concentration. In the second patient ( $p a-$. lient $B$ ), the remnant appeared to be unable to restore euthyroidism even with maximal TSH stimulation. Administration of exogenous thyroid hormone begun 2 months following surgery resulted in a prompt return of both $\mathrm{TSH}$ and $\mathrm{T}_{4}$ to the normal range. The third patient behaved in a similar fashion. Both of these latter patients after I year of thyroid replacement therapy failed to maintain euthyroidism when treatment was discontinued. The first patient, on the other hand, has not required thyroid replacement therapy at any time during a follow-up of similar length.

\section{Single Thyroid Nodules}

The two patients with thyroid nodules were euthyroid on presentation. After hemithyroidectomy, serial measurements of $\mathrm{TSH}$ and $\mathrm{T}_{4}$ failed to show an elevation of TSH above the normal range. In a follow-up of a year's duration, both have remained clinically and chemically euthyroid.

\section{Congenital Hypothyroidism}

Initial laboratory data and the responses to therapy of two untreated congenitally hypothyroid infants are shown in Figure 5. Treatment was in accord with the recommended schedule of gradually increasing doses of thyroid in patient $A$. Patient $B$ received a loading dose of parenteral $\mathrm{T}_{4}$ followed by a full oral replacement dose of a preparation combining $T_{4}$ and triiodothyronine $\left(T_{3}\right)$. The most striking feature of these data is the difference in time from the initiation of treatment to the return of the TSH levels to normal. The first normal level was recorded 9 weeks after beginning therapy in the child treated by the conventional schedule whereas the second infant showed a sharp decline in the TSH after only 3 days of treatment. No adverse side effects were seen in the child who received the loading $\mathrm{T}_{4}$ dose.

Data on 10 congenitally hypothyroid patients who had been treated with desiccated thyroid since early infancy are shown in Figure 6. Eight of the ten showed a brisk rise in TSH 2 weeks after discontinuation of therapy. Normalization of the TSH concentration was seen on sampling 2 weeks later after restarting exogenous thyroid at full replacement doses. One of the two patients who did not respond to discontinuation of therapy was later reinvestigated and a rise to high level of TSH was seen at 3 weeks. Even after 3 weeks the other patient did not show a rise in TSH. Subsequent investigations have shown no response to administration of thyrotropin releasing factor and thus indicate that here hypothyroidism is secondary to selective TSH deficiency.

\section{Ectopic Thyroid Tissue}

In the two patients with sublingual goiters, concentrations of TSH above $80 \mathrm{ng} / \mathrm{ml}$ in one and of 30 $\mathrm{ng} / \mathrm{ml}$ in the other were found 2 weeks after discontinuation of thyroid. Return to normal values on reinsti- 

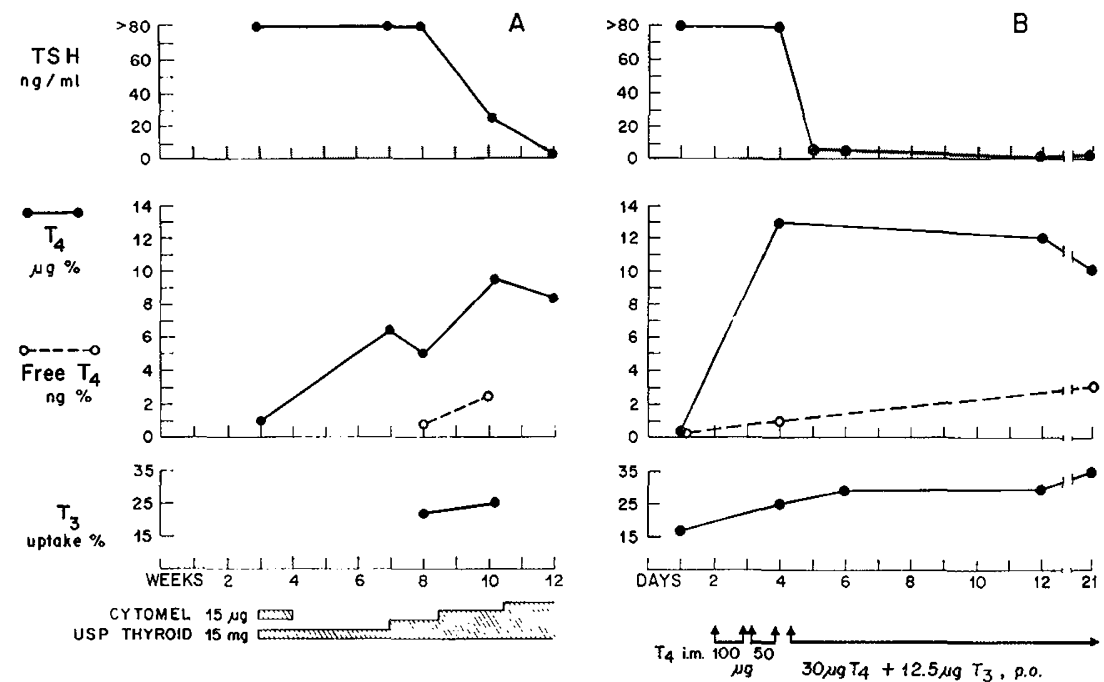

Fig. 5. Responses in congenital hypothyroidism to two methods of treatment. A: Infant diagnosed at age 3 weeks and treated conventionally. Note failure of TSH to decline to normal until 9 weeks after institution of treatment regimen. $B$ : Patient diagnosed at age 18 weeks. Note the restoration to normal of thyroid stimulating hormone (TSH) 3 days after parenteral thyroxine $\left(T_{4}\right)$ loading doses. $T_{3}:$ Triiodothyronine.

tution of therapy followed the same pattern as in the athyreotic patients.

\section{Secondary Hypothyroidism}

All five patients in this group (Fig. 1) showed TSH values of less than $3.7 \mathrm{ng} / \mathrm{ml}$ in the presence of subnormal $\mathrm{T}_{4}$ serum concentrations.

\section{Juvenile Hypothyroidism}

Figure 7 shows the biochemical responses to thyroid hormone administration in the two females with longstanding juvenile acquired hypothyroidism. Treatment was begun by administering an intramuscular loading dose of $T_{4}$ designed to restore the serum total thyroxine to normal. In both, within $72 \mathrm{hr}$ after the $\mathrm{T}_{4}$ was given, the TSH had declined into the normal

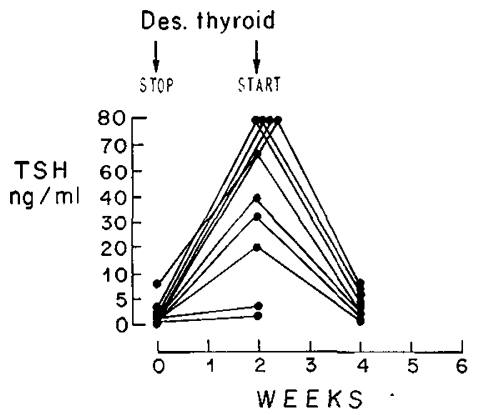

Fig. 6. Thyroid stimulating hormone $(T S H)$ response in previously treated congenitally hypothyroid children. Therapy was abruptly discontinued after the first blood sample and reinstithited immediately after the second.

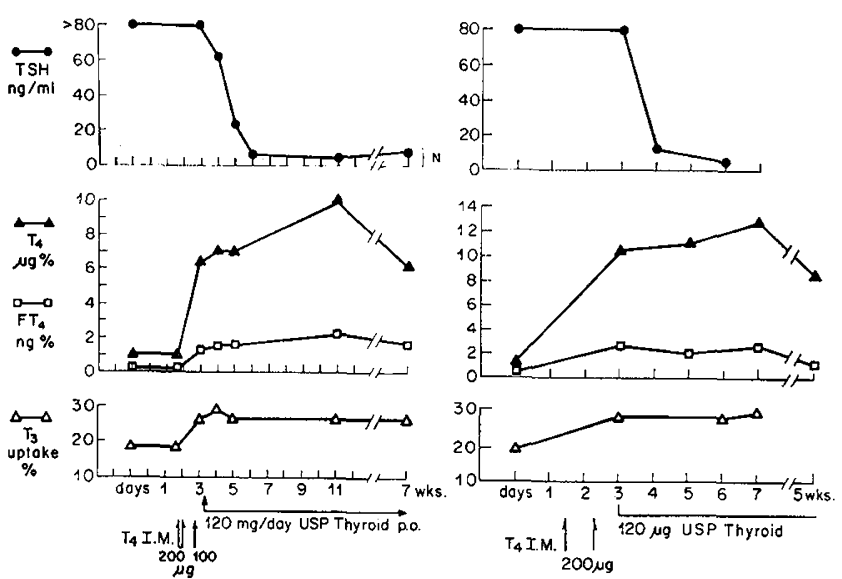

Fig. 7. Changes in plasma thyroid stimulating hormone (TSH), serum thyroxine $\left(T_{4}\right)$, free thyroxine $\left(F T_{4}\right)$, and triiodothyronine resin uptake $\left(T_{3} U\right)$ in two patients with previously untreated juvenile hypothyroidism. In both, treatment was initiated with loading doses of $T_{4}$ given intramuscularly followed by full oral replacement therapy. Note the rapid decline in TSH to normal levels $72 \mathrm{hr}$ after beginning treatment and the absence of rise of the $\mathrm{FT}_{4}$ and $\mathrm{T}_{3} \mathrm{U}$ values above normal despite elevation of the $T_{4}$ to thyrotoxic levels in the patient for whom data are shown on the right. The patient for whom data are shown at the left was 12 years old at the time of treatment; the sccond patient was 5.5 years old.

range. In the 5.5-year-old girl (Fig. 7, right-hand panel) the $T_{4}$ rose into the hyperthyroid range $(12.5 \mu \mathrm{g} / 100$ $\mathrm{ml}$ on the 5th day posttherapy) but $\mathrm{FT}_{4}$ and $\mathrm{T}_{3} \mathrm{U}$ remained in the normal range and she showed no clinical signs of hyperthyroidism. No adverse effects were 

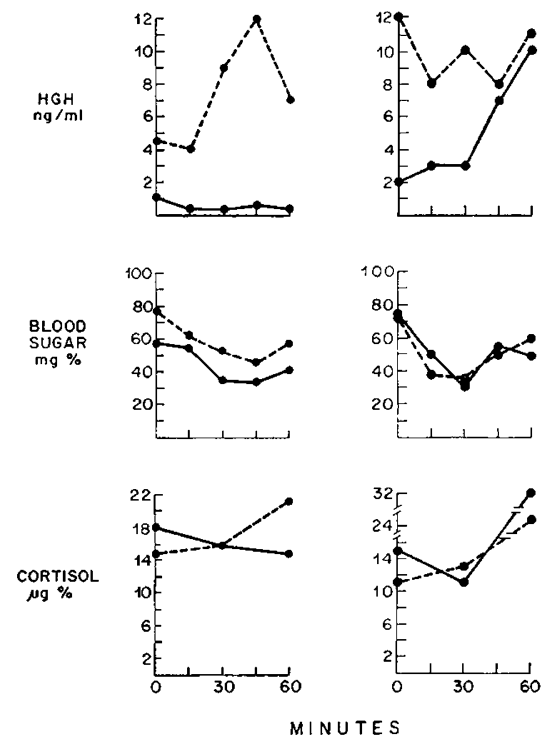

Fig. 8. Response of growth hormone $(H G H)$ and cortisol to insulin-induced hypoglycemia in two patients with juvenile myxedema before (- - ) and $72 \mathrm{hr}$ after treatment $(\bullet---\bullet)$ initiated with a large loading dose of $\mathbf{T}_{4}$. The left-hand panel refers to the responses of the 12-year-old girl, the right-hand shows those of the 5.5-year-old girl whose treatment is detailed in Fig. 7.

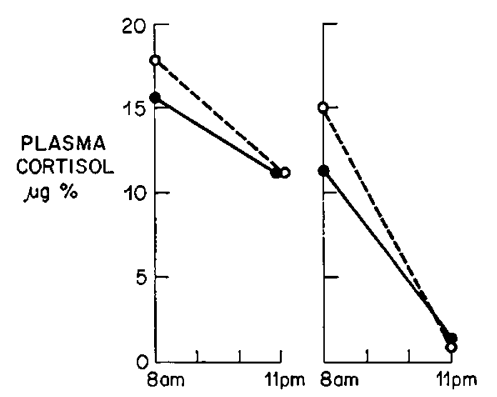

Fig. 9. Cortisol circadian rhythms in the two patients with myxedema of Figs. 7 and 8. Data obtained before therapy (thyroid stimulating hormone $(T S H)>80 \mathrm{ng} / \mathrm{ml}$ ) are given in the lefthand panel; data pertaining to $72 \mathrm{hr}$ posttherapy (TSH $<5 \mathrm{ng}$ / $\mathrm{ml}$ ) by the right-hand panel.

attributable to this therapy and within $72 \mathrm{hr}$ both of the patients exhibited a marked increase in energy and activity as well as improvement in the briskness of the relaxation phase of the deep tendon reflexes.

Insulin-tolerance tests were performed on these two girls; the first, before, and the second, $72 \mathrm{hr}$ after starting treatment when the TSH concentration had fallen to normal. The results are seen in Figure 8 where it can be seen that the HGH response was blunted in the presence of hypothyroidism. The degree of impairment in HGH secretion appeared to parallel the severity of the myxedema, inasmuch as the 5.5-year-old patient in whom $\mathrm{HGH}$ levels were higher was clinically less severely hypothyroid than the older girl. Both normal and blunted HGH responses in hypothyroidism are reported in the literature $[1,18,25]$ and the divergence of results may be related, as here, to differing degrees of thyroid insufficiency at the times of study.

Figure 8 also shows that the response of plasma cortisol to hypoglycemia is impaired in severe myxedema. However, data concerning the alteration of the metabolism of cortisol are shown in Figure 9. Evening hypercortisolism with plasma values in the range of $11 \mu \mathrm{g} /$ $100 \mathrm{ml}$ (normal $=5 \mu \mathrm{g} / 100 \mathrm{ml}$ ) was seen in both patients prior to treatment. Abrupt restoration of euthyroidism returned the cyclic variation of plasma cortisol values to normal coincident with the decline of serum TSH.

Data on plasma LH are shown in Figure 10 for the same two girls. It can be seen that these values clearly exceeded the normal prepubertal levels $(6 \mathrm{mIU} / \mathrm{ml})$ and that with treatment their decline toward normal was slowly progressive over a period of weeks in sharp contrast to the more rapid restoration to normal of the other pituitary hormonal responses. The pretreatment concentration of $\mathrm{LH}$ in the male patient was also high at $20 \mathrm{mIU} / \mathrm{ml}$. Three months after starting treatment

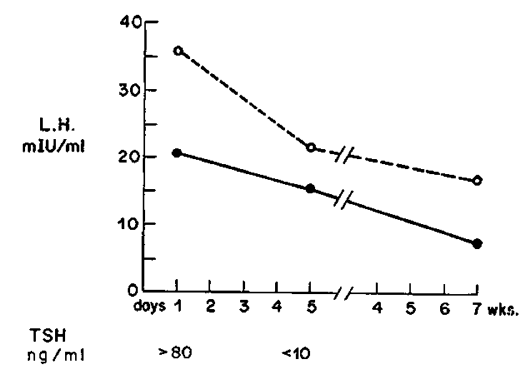

Fig. 10. Plasma luteinizing hormone (L.H.) values in the two prepuberal girls with hypothyroidism (Figs. 7-9) followed over a period of 7 weeks after initiation of therapy. TSH: Thyroid stimulating hormone.
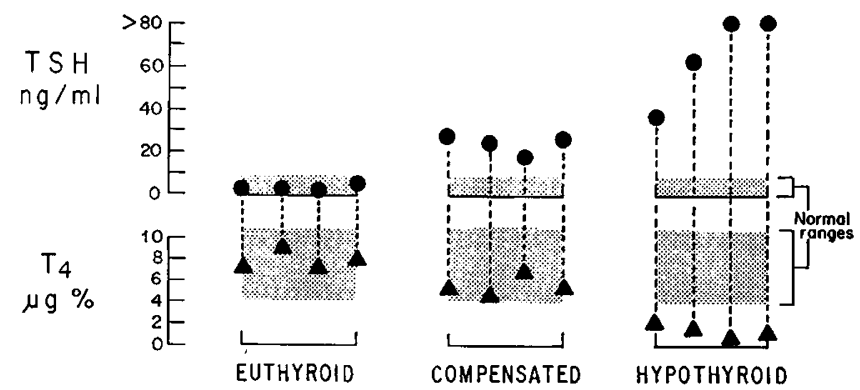

Fig. 11. Thyroid stimulating hormone (TSH) and serum thyroxine $\left(T_{4}\right)$ measurements in 12 patients with Hashimoto's thyroiditis showing segregation into three groups. 
there had been no change in testicular size but the plasma LH had declined to $7.4 \mathrm{mIU} / \mathrm{ml}$.

\section{Hashimoto's Thyroiditis}

The 12 patients with a diagnosis of Hashimoto's thyroiditis were divisible into three groups (Fig. 11) in accordance with their TSH and $\mathrm{T}_{4}$ measurements. The first group, classified as euthyroid, had normal TSH and $\mathrm{T}_{4}$ levels. The second group, also comprised of clinically euthyroid patients, has been called compensated since it appeared that the normal $\mathrm{T}_{4}$ concentration was maintained at the expense of a moderate TSH overstimulation. The third group consisted of patients with frank clinical hypothyroidism, subnormal $\mathrm{T}_{4}$ values, and elevated levels of TSH.

Similar results have recently been reported by Greenberg et al. [11] in 32 children with histologically proven chronic lymphocytic thyroiditis. In the "compensated group," however, we found that on repeated sampling at one time or another, each of the four patients showed a spontaneous return of the TSH to a normal level while the $T_{4}$ increased to a higher value but within the normal range. One of these girls has been studied with serial TSH and $\mathrm{T}_{4}$ determinations over a period of 8 months and has manifested a regular pattern of fluctuation between the euthyroid and compensated classification with cycles ranging between 3 and 4 weeks in length.

\section{Discussion}

The results shown in the foregoing section indicate that knowledge of TSH concentrations is particularly useful in the evaluation of hypothyroid states, and of help, too, in several of the other thyroid disorders that affect children.

Our failure to find evidence of a circadian rhythm or to augment $\mathrm{TSH}$ release by means of hypoglycemia or aminoacid loading parallels results which have been obtained in adults [30]. Other stimuli such as electroshock [34], methimazole, methimazole-iodide, vasopressin, and glucagon have been equally unsuccessful [35]. The advent of supplies of natural and synthetic TSH releasing factor for clinical use has for the first time provided a means for rapid assessment of the pituitary TSH reserve in children [5].

The association of hyperthyroidism and excessive TSH production has been documented twice by bioassay $[19,23]$ and in one case by radioimmunoassay [12] in three adults with pituitary tumors. This rare combination has also been encountered in children. In 1964,
Nyhan and Green [27] reported on an 11-year-old child with a pituitary chromophobe adenoma and hyperthyroidism. In reviewing the literature these authors found two additional cases in childhood and suggested that examination of visual fields and x-rays of the skull be obtained in order to uncover this association in children with thyrotoxicosis. Since all values in our children with thyrotoxicosis have fallen below the $5 \mathrm{ng} / \mathrm{ml}$ level, it would appear that these examinations need be conducted only in those patients in whom the TSH concentration is elevated.

Periodic determinations of TSH were of great usefulness in adjustment of medical therapy once the diagnosis of hyperthyroidism was confirmed by standard laboratory tests. We now recognize that a rise in TSH level to greater than $10 \mathrm{ng} / \mathrm{ml}$ after initiation of antithyroid drug therapy is an indication for a decrease in the dose or for addition of exogenous thyroid sufficient to return TSH to normal. Maneuvers such as these which succeed in restoring the TSH to the normal range make possible a degree of clinical stability during the long course of medical management of thyrotoxicosis which is difficult to achieve using other parameters of response.

The data of Utiger [40] and more recently of Slingerland et al. [37] indicate that TSH determinations are useful in assessing thyroid function in the long term follow-up of radioiodine-treated patients. These authors have shown that a failing thyroid gland can maintain euthyroidism at the expense of elevated TSH levels; a state of preclinical hypothyroidism has been suggested to describe this situation which appears currently to be present in the subject of Figure 3. The status of the patients with Hashimoto's thyroiditis with what we have termed compensated euthyroidism (Fig. 11) appears to be analogous.

Our data for the surgically treated patients, although preliminary, would indicate that determination of $\mathrm{TSH}$ and $\mathrm{T}_{4}$ as soon as 2 weeks postoperatively may provide an important prognostic guide with regard to whether the patient will develop future permanent hypothyroidism or remain euthyroid. The data of Figure 4 indicate that subnormality of $T_{4}$ with an elevated TSH level presages the development of hypothyroidism. Similar data have been published in a long term follow-up study of hyperthyroid adult patients after subtotal thyroidectomy [15].

Persistence of euthyroidism after hemithyroidectomy without significant change in thyroid parameters is not surprising, since it appears that as little as $5 \mathrm{~g}$ thyroid 
tissue are sufficient to provide adequate thyroid hormone for bodily needs.

Results of treatment in the congenitally hypothyroid infants disclose that there is a full functional development of the hypothalamic-pituitary-thyroidal axis at birth despite prenatal thyroid insufficiency severe enough to retard skeletal maturation. Although the elevated level of TSH persisting for 9 weeks in the cretinous infant given conventional treatment (Fig. 5, patient $A$ ) might have been interpreted as due to immaturity of this axis, especially during that period when the $T_{4}$ had risen into the normal range, the brisk fall in TSH in the second baby clearly indicates the functional integrity of the feedback system and emphasizes the greater capacity for discrimination of the euthyroid state provided by the TSH as contrasted by the $\mathrm{T}_{4}$ determination.

In the older patients with previously treated congenital hypothroidism, the data of Figure 6 indicate that years of continuous suppression of pituitary TSH has no effect on the normal function of the feedback mechanism.

The observations on the patients with sublingual goiters are essentially similar to data obtained by Kulin et al. [22]. Our patients, like theirs, showed a prompt rise in TSH on discontinuing thyroid, thus strengthening the evidence against TSH deficiency as a cause of in utero thyroid dysgenesis.

Because reports on urinary gonadotropins in juvenile myxedema have been conflicting, it was of special interest to measure the plasma gonadotropins in the course of the present study. The demonstration of uniformly high LH plasma values (Figure 10) suggests that the pituitary does secrete heterologous hormones in response to a single target organ failure as originally postulated by Van Wyck and Grumbach [42], providing chemical confirmation of the so-called "overlap syndrome." It was of further interest to find that while rapid return to euthyroidism restored cortisol and $\mathrm{HGH}$ responses to normal in a period as short as $72 \mathrm{hr}$, the decline in plasma LH was accomplished more slowly, taking as long as 7 weeks.

It could be argued that the initial high LH values represent cross reactivity in the TSH radioimmunoassay; however, although this might account for elevated LH levels when the TSH was high it would not explain their continued elevation after treatment with thyroid and the abrupt lowering of TSH. Furthermore, the possibility of cross-reaction has been reduced in the design of the method by absorbing the TSH antiserum with $H C G[6,31]$ and $L H$ antigens $[31,36]$.
Histologic evidence suggests that even in infancy there is active release of gonadotropins by the pituitary gland in untreated hypothyroidism [33] and evidence of ovarian stimulation by gonadotropin has been reported in a cretin only 13 weeks old [2].

The results of the plasma cortisol measurements could be interpreted as reflecting the impaired peripheral cortisol metabolism which has been reported in untreated hypothyroid children [20]. However, a direct effect on the amount and periodicity of pituitary adrenocorticotropic hormone (ACTH) secretion could play a role in the evening hypercortisolism. This possibility cannot be directly assessed since ACTH measurements were not carried out, but the data of Martin et al. [25] indicate that ACTH secretion as demonstrated by SU 4885 stimulation is impaired by hypothyroidism. Possibly, a combination of these two factors accounts for the lack of circadian variation.

The observations on children affected with Hashimoto's thyroiditis indicate a clear need for replacement therapy in the hypothyroid group. Our experience and that of others [11,23] has suggested that chronic suppressive doses of thyroid hormone do not improve the prognosis in the euthyroid and compensated groups. Although there appears to be movement of the patients with high TSH and low normal $\mathrm{T}_{4}$ levels back to biochemical normalcy from time to time, the long term trend of the majority of patients is in the opposite direction, towards hypothyroidism. If this is true, therapy may be indicated in the compensated patient when serial measurements indicate euthyroidism is the product of high levels of TSH.

\section{Summary}

TSH determinations have proven to be of value in the diagnosis, management, and prognosis of children affected with thyroid disorders. Normal values have a sharply defined upper limit and no overlap with those of patients with primary hypothyroidism. Pituitary secretory function investigated in severe juvenile myxedema revealed generalized disturbances in direct consequence of the single target gland failure.

\section{References and Notes}

I. Brauman, H., and Corvil.ain, J.: Growth hormone response to hypoglycemia in myxedema. J. Clin. Endocrinol., 28: 301 (1968).

2. Burt, A. S., AND COHEN, R. B.: Pituitary changes in thyroid aplasia: possible significance. Lab. Invest., 2: 357 (1953).

3. Cassidy, C. E., Benotti, J., and Peno, S.: Clinical evaluation of the determination of thyroxine iodine. J. Clin. Endocrinol., 28: 420 (1968). 
4. Catr, K. J., Niall, H. D., and Treager, G. W.: Solid phase radioimmunoassay of human growth hormone. Biochem. J., 100: 316 (1966).

5. Costom, B. H., Grumbach, M. M., and Kaplan, S. L.: Effect of thyrotropin-releasing factor (TRF) on serum thyroid stimulating hormone. An approach to distinguishing hypothalamic from pituitary forms of idiopathic dwarfism. J. Clin. Invest., 50: 2219 (1971).

6. Czernichow, P., Greenberg, A. H., Tyson, J., and Blizzard, R. M.: Thyroid function studied in paired maternal-cord sera and sequential observations of thyrotropin hormone release during the first 72 hours of life. Pediat. Res., 5: 53 (1971).

7. Fisher, D. A., Hobel, C. J., Garza, R., and Pierce, C. A.: Thyroid functions in the preterm fetus. Pediatrics, 64: 208 (1970).

8. Fisher, D. A., AND Odell, W. D.: Acute release of thyrotropin in the newborn. J. Clin. Invest., 48: 1670 (1969).

9. Fisher, D. A., Odell, W. D., Hobel, C. J., AND Garza, R.: Thyroid function in the term fetus. Pediatrics, 44: 526 (1969).

I0. Fukuchi, M., Inove, T., Abe, H., and Kumahara, Y.: Thyrotropin in human fetal pituitaries. J. Clin. Endocrinol, 31: 565 (1970).

11. Greenberg, A. H., Czernichow, P., Hung, W., Shelley, W., Winship, T., AND Blizzard, R. M.: Juvenile chronic lymphocytic throiditis: clinical, laboratory and histological correlations. J. Clin. Endocrinol., 30: 293 (1970).

12. Hamilton, C. A., Adams, L. C., and Maloof, F.: Hyperthyroidism due to thyrotropin-producing pituitary chromophobe adenoma. New Engl. J. Med., 283: 1077 (1970).

13. HaYek, A., Bauman, R. A., ANd CRawford, J. D.: ${ }^{90 m} \mathrm{Tc}$ pertechnetate for detection of cryptic thyroid tissue in childhood hypothyroidism. J. Pediat., 79: 466 (1971).

14. Hayek, A., Chapman, E. M., and Crawford, J. D.: Long term results of treatment of thyrotoxicosis in children and adolescents with radioactive iodine. New Engl. J. Med., 283: 949 (1970).

15. Hedley, A. J., Hall, R., Amos, J., Michie, W., and Crooks, J.: Serum thyrotropin levels after subtotal thyroidectomy for Graves' disease. Lancet, $i$ : 455 (1971).

16. Hershman, J. M., and Pittman, J. A.: Utility of the radioimmunoassay of serum thyrotropin in man. Ann. Int. Med., 74: $481(1970)$.

17. Hunter, W. M., and Greenwood, F. C.: Preparation of iodineI31 labelled growth hormone of high specific activity. Nature, 194: 495 (1962).

18. Itwatsubo, H., Omori, K., OKada, Y., Fukuchi, M., Miyai, K., Abe, H., and Kumahara, Y.: Human growth hormone secretion in primary hypothyroidism before and after treatment. J. Clin. Endocrinol., 27: 1751 (1967).

19. JAiler, J. W., AND Holub, D. A.: Remission of Graves' disease following radiotherapy for a pituitary neoplasm. Amer. J. Med., 28: 497 (1960).

20. Kenny, F. M., Iturzaeta, N., Preeyasombar, C., Taylor, F. M., AND Migeon, C. J.: Cortisol production VII. Hypothyroidism and hyperthyroidism in infants and children. J. Clin. Endocrinol., $27: 1616$ (1967).

21. Kliman, B.: Recent advances in the double isotope derivatives analysis of steroids. Advan. Tracer Methodol., 4: 227 (1968).

22. Kulin, H. E., Kohler, P. O., O'Malley, B. W., and Odell,
W. D.: Thyroid stimulating hormone in thyroid dysgenesis. J. Pediat., 71: 714 (1967).

23. Lamberg, B. A., Ripatti, J., Gordin, A., Juustila, H., Sivula, A., ANd Bjorkesten, G.: Pituitary adenoma with acromegaly and TSH induced hyperthyroidism associated with parathy. roid adenoma. Acta Endocrinol., 60: 157 (1969).

24. Ling, S. M., Kaplan, S. A., Weitzman, J. J., Reed, G. B., Costin, G., AND Landing, B.: Euthyroid goiters in children: correlation of needle biopsy with other clinical and labora. tory findings in chronic lymphocytic thyroiditis and simple goiter. Pediatrics, 44: 695 (1969).

25. Macgillivray, M. H., Aceto, T., and Frohman, L. A.: Plasma growth hormone responses and growth retardation of hypothyroidism. Amer. J. Dis. Child., 115: 273 (1968).

26. Martin, M. M., AND MinTz, D. H.: Effect of altered thyroid function upon adrenocortical ACTH and methopyrapone (SU 4885) responsiveness in man. J. Clin. Endocrinol., 25: 20 (1965).

27. Nyhan, W. L., ANd GReEN, M.: Hyperthyroidism in a patient with a pituitary adenoma. J. Pediat., 65: 583 (1964).

28. Odell, W. D., Ross, G. T., and Rayford, P. L.: Radioimmunoassay for luteinizing hormone in human plasma or serum: physiological studies. J. Clin. Invest., 64: 248 (1967).

29. Odell, W. D., Wilber, J. F., and PaUl, W. E.: Radioimmunoassay of thyrotropin in serum. J. Clin. Endocrinol., 25: 1179 (1965).

30. Odell, W. D., Wilber, J. F., ANd Utiger, R.: Studies of thyrotropin physiology by means of radioimmunoassay. Recent Progr. Hormone Res., 23: 47 (1967).

31. Odell, W. D., Vanslager, L., and Bates, R.: Radioimmunoassay of human thyrotropin. Atomic Energy Comm. Symp. Ser., 13: 185 (1968).

32. Petricciani, J. C., Aceto, T., Macgrllivray, M. H., and WAGNER, H.: Treatment of young cretins with triiodothyronine. Metabolism, 20:678 (1971).

33. Russfield, A. B.: Histology of the human hypophysis in thyroid disease-hypothyroidism, hyperthyroidism, and cancer. J. Clin. Endocrinol., 15: 1393 (1955).

34. Ryan, R. J., Swanson, D. W., Faiman, C., Mayberry, W. E., and Spadoni, A. J.: Effects of convulsive electroshock on serum concentrations of follicle stimulating hormone, luteinizing hormone, thyroid stimulating hormone and growth hormone in man. J. Clin. Endocrinol., 30: 51 (1970).

35. Sawin, C. T., Hershman, J. M., Handler, S. D., and Utiger, R. D.: Attempts to augment thyrotropin secretion: Effects of methimazole, methimazole-iodide, vasopressin, and glucagon. Metabolism, 19: 488 (1970).

36. Schalch, D. S., Parlow, A. F., Boon, R. C. and Reichlin, S.: Measurement of human luteinizing hormone in plasma by radioimmunoassay. J. Clin. Invest., 47: 665 (1968).

37. Slingerland, D. W., Dell, E. S., and Burrows, B. A.: The spectrum of thyroid function after radioiodine treatment. In: W. K. Felling and R. Höfer: Further Advances in Thyroid Rescarch, Vol. 2, p. 993. (Verlag der Wiener Medizinischen Akademie, Vienna, 1971).

38. Sterling, K., And Brenner, M. A.: Free thyroxine in human serum: simplified measurement with the aid of magnesium precipitation. J. Clin. Invest., 45: 153 (1966).

39. Utiger, R. D.: Radioimmunoassay of human plasma thyrotropin. J. Clin. Invest., 44: 1277 (1965). 
40. Utiger, R, D.: Plasma TSH in health and disease: immunoassay studies. In: C. Gual and F. J. G. Ebling: Progress in Endocrinology, p. 1186. (Excerpta Medica Foundation, Amsterdam, 1968).

41. Valloton, M. B., Pretell, J. Y., and Forbes, A. P.: Distinction between idiopathic primary myxedema and secondary pituitary hypothyroidism by the presence of circulating thyroid antibodies. J. Clin. Endocrinol., 27: I (1967).

42. VAN WyK, J. J., and Grumbach, M. M.: Syndrome of precocious menstruation and galactorrhea in juvenile hypothyroidism: an example of hormonal overlap in pituitary feedback. J. Pediat., 57: 416 (1960).

43. Human thyroid stimulating hormone (h-TSH) and anti-hTSH were kindly supplied by the Endocrinology Study Section, National Pituitary Agency, NIAMD.

44. Human Thyrotropin Research Standard A was obtained from The Division of Biological Standards, National Institute for Medical Research, Mill Hill, London, England.

45. Measured at the Boston Medical Laboratory, Waltham, Mass.

46. Determined by the Abbott Trisorb Kit method.

47. Determined by the New England Nuclear Corporation, Biomedical Assay Laboratories Division, Worcester, Mass.

48. The authors are indebted to Mr. L. Adams, Mr. A. McCamman, and Mr. C. M. Rack for the TSH radioimmunoassays.

49. This work was supported in part by United States Public Health Service Grant nos. HD TOl 00033, AM 4501, AM 13916-01, and HD 05195-0I of the United States Public Health Service and by the Shriners Burns Institute, Boston Unit.

50. Requests for reprints should be addressed to: JoHn D. CRAwFORD, M.D., Childrens Service, Massachusetts General Hospital, Fruit St., Boston, Mass. 02114 (USA).

51. Accepted for publication September 29, 1972. 